\title{
Computing Curricula 2001: Computer Engineering
}

\author{
Joseph L. A. Hughes / Pradip K. Srimani \\ School of Electrical and Computer Engineering / Dept. of Computer Science \\ Georgia Institute of Technology / Clemson University
}

The Computing Curricula 2001 (CC2001) Task Force [1] was established in 1998 by the Association for Computing Machinery and the Computer Society of the Institute for Electrical and Electronics Engineers. The goal of the task force was to develop a set of curricular guidelines that would "match the latest developments of computing technologies in the past decade and endure through the next decade." Similar efforts a decade earlier had focused on computer science, however, the current effort is developing a series of volumes defining curricular guidelines for several disciplines within the computing field. A committee was established in 2001 to focus on the computer engineering volume, including defining the body of knowledge that constitutes computer engineering and identifying examples of course and curricular implementations.

One of the primary objectives is to define computer engineering as a discipline, distinct from the fields of electrical engineering and computer science, while acknowledging both the historical and ongoing connections to these fields. As a basis for curriculum development, it is important that computer engineering be defined in terms of the unique knowledge and activities it embodies, rather than as a subset or intersection of courses from other fields. Computer engineering embodies the science and the technology of design, construction, implementation and maintenance of the hardware and the software components of modern computing systems and computercontrolled equipment. Computer engineers are solidly grounded in the theories and principles of computing, mathematics and engineering, and apply these theoretical principles to design hardware, software, networks, and computerized equipment and instruments to solve technical problems in diverse application domains. Continuing dramatic advances in computing and digital systems design have created opportunities for computer engineering professionals to apply their knowledge across the entire range of applications in engineering.

The development of a successful computer engineering curriculum requires an understanding of the unique nature of this discipline. Computer engineering focuses on the design of computing elements and computer based systems; it integrates hardware and software and provides human systems interfaces to produce efficient cost-effective total systems to solve technical problems in diverse application domains. Computer engineering programs require a strong foundational component in science and mathematics, emphasize design and creativity, and incorporate strong laboratory experiences throughout the program using modern laboratory environments and industry-standard design and maintenance tools.

Proceedings of the 2002 American Society for Engineering Education Annual Conference \& Exposition Copyright (C) 2002, American Society for Engineering Education 
As with the other volumes, the computer engineering body of knowledge is organized hierarchically into three levels: disciplinary sub fields (e.g., digital logic), units or thematic modules within an area (e.g., switching theory) and topics (lowest hierarchical level within a unit, e.g., number systems). Units are designated "core" (to be covered in all computer engineering programs) and "elective" (inclusion depends on program objectives). The committee also has developed a list of principles that will guide the entire curriculum development process and plans to provide guidelines on expected characteristics of graduates, the role of professional practice, mathematics and science requirements, and implementation issues. While there will be many ways to organize and present the material from the body of knowledge, the finished volume will provide examples of successful implementations in the form of courses and curricula.

The usefulness of the finished volume depends heavily on its acceptance and usefulness across the full range of computer engineering programs. Committee members, listed in Table 1, were selected to encompass a variety of technical specialties within computer engineering, electrical engineering, and computer science. Their institutions and programs are reflective of the diversity among academic institutions. Several members of the committee are actively involved in engineering accreditation or have experience in academic administration. Additionally, contributions to specific elements of the body of knowledge have been solicited from other individuals and the draft document will be available for review by educators and practitioners in the discipline.

Table 1. Members of the CC2001 Computer Engineering Committee.

Dave Soldan (chair), Kansas State University
Mitch Theys (editor), Univ. of Illinois at Chicago
Jim Aylor, University of Virginia
Alan Clements, University of Teesside (England)
Gerald Engel, University of Connecticut
Ron Hoelzeman, University of Pittsburgh
John Impagliazzo, Hofstra University
Esther Hughes, Virginia Commonwealth University

Joseph Hughes, Georgia Institute of Technology Bob Klenke, Virginia Commonwealth University Andrew McGettrick, U. of Strathclyde (Scotland) Danial Neebel, Loras College Victor Nelson, Auburn University Bob Sloan, University of Illinois at Chicago Pradip Srimani, Clemson University Murali Varanasi, University of South Florida

The CC2001 computer science volume was approved in December 2001 and the goal is to complete the final draft of the computer engineering volume by the end of 2002. A "strawman" draft, including both the computer engineering body of knowledge and major report sections, is planned for approximately the time of the 2002 ASEE Annual Conference. The conference presentation will describe the overall project, the status of the computer engineering volume, and plans for review of the volume. It also will provide an opportunity for members of the computer engineering community to provide suggestions and comments on the computer engineering volume and to participate in the review process.

[1] http://www.computer.org/education/cc2001/

Proceedings of the 2002 American Society for Engineering Education Annual Conference \& Exposition Copyright (C) 2002, American Society for Engineering Education 
JOSEPH L. A. HUGHES is Associate Professor and Associate Chair for Computer Engineering and Program Development in the School of Electrical and Computer Engineering at Georgia Institute of Technology, Atlanta. $\mathrm{He}$ is actively involved in program accreditation and assessment activities. He received his Ph.D. in electrical engineering from Stanford University in 1986. email: joe.hughes@ece.gatech.edu

PRADIP K. SRIMANI is Professor and Chair of the Department of Computer Science at Clemson University, Clemson, South Carolina. His primary research interests are in parallel and distributed computing. He received his Ph.D. in computer science from the University of Calcutta in 1978. email: srimani@cs.clemson.edu 